\title{
Our Experience of Passage on the B-Theory
}

\author{
Natalja Deng
}

Received: 29 June 2010/ Accepted: 15 April 2013/Published online: 18 May 2013

(C) Springer Science+Business Media Dordrecht 2013

\begin{abstract}
Elsewhere I have suggested that the B-theory includes a notion of passage, by virtue of including succession. Here, I provide further support for that claim by showing that uncontroversial elements of the B-theory straightforwardly ground a veridical sense of passage. First, I argue that the B-theory predicts that subjects of experience have a sense of passivity with respect to time that they do not have with respect to space, which they are right to have, even according to the B-theory. I then ask what else might be involved in our experience of time as passing that is not yet vindicated by the B-theoretic conception. I examine a recent B-theoretic explanation of our 'illusory' sense of passage, by Robin Le Poidevin, and argue that it explains away too much: our perception of succession poses no more of a problem on the B-theory than it does on other theories of time. Finally, I respond to an objection by Oreste Fiocco that a causal account of our sense of passage cannot succeed, because it leaves out the 'phenomenological novelty' of each moment.
\end{abstract}

\section{Introduction}

Contemporary analytic metaphysics of time is shaped by the debate between A-theorists and B-theorists.

The B-theory of time is characterized by the following three tenets:

1. A-determinations such as 'past', 'present', and 'future' do not denote monadic temporal properties or any other objective and mind-independent aspects of temporal reality - they are merely perspectival terms, just like 'here' and 'there'.

\footnotetext{
N. Deng $(\bowtie)$

Département de Philosophie, Université de Genève, 2 rue de Candolle, 1205 Geneva, Switzerland e-mail: nmd24@cantab.net
} 
2. All times exist and are equally real, i.e. all times are ontologically on a par;

3. There are only tenseless facts. Typical examples of tenseless facts include the fact that your reading this sentence \{occurs \} on (say) a Monday, and the fact that my writing it \{precedes your reading it by a certain number of months and days. (I'll sometimes use curly brackets to indicate tenseless predication.)

The A-versus B-debate is widely construed as a debate about whether or not time passes, whether or not time has a dynamic aspect. Accordingly, B-theorists often either deny that we experience time as passing, or try to explain that aspect of experience away, treating it as in some sense illusory.

It is my view that B-theorists need do neither. They can acknowledge that we experience time as passing, and take that aspect of experience to be entirely veridical. In a way this is not surprising, since I advocate a version of the B-theory on which it includes passage by virtue of including succession. But I do not presuppose that view of the B-theory in this paper. Here, my strategy will be to build up a picture of veridical elements of temporal experience on the B-theory (as it is commonly understood), and show that nothing is left out by that picture.

First, I argue that the B-theory predicts that subjects of experience have a sense of passivity with respect to time that they do not have with respect to space, which they are right to have, even according to the B-theory (Sect. 2). I then ask what else might be involved in our experience of time as passing that is not yet vindicated by the B-theoretic conception. I examine a recent B-theoretic explanation of our 'illusory' sense of passage, by Robin Le Poidevin, and argue that it explains away too much: our perception of succession poses no more of a problem on the B-theory than it does on other theories of time (Sect. 3). The upshot will be that if there is dynamicity involved in our perception of succession, then it too is a veridical aspect of experience on the B-theory. Finally, I respond to an objection by Oreste Fiocco that a causal account of our sense of passage cannot succeed, because it leaves out the 'phenomenological novelty' of each moment (Sect. 4).

\section{A Feeling of Passivity}

On the B-theory, times and/or events stand in dyadic B-theoretic relations to other times and/or events; there are only tenseless facts; and all times are equally real. How do a person's experiences fit into such a conception? (I'll assume that experiences are events, and that like events generally, experiences vary in temporal extent: some happen over shorter intervals than others.)

For simplicity, let's consider subjects who are not unconscious at any moment during their lives. Now, consider the shortest time interval that an experience can last so as to still be accessible to the subject by introspection; for example, consider your experience of reading this sentence, at this moment. I am thinking of what is sometimes called 'the experienced present' (or, by some authors, 'the specious present'). Then we can in principle divide up each person's life into a number of experiences that are as brief as this (let me call them 'momentary (temporal) 
experiences'), where these experiences are events which, according to the B-theory, stand in dyadic temporal relations of precedence and succession to one another.

These momentary experiences will typically have varying contents, but there are some common aspects. At any given time, i.e. at any given moment, the subject's temporal experience has a content that is to a large extent shaped by perceptions and actions, memories and anticipations at that time, including any tensed beliefs that may be involved in these, as well as by all other tensed beliefs that the subject has at that time. Each such time, with its accompanying momentary experience, constitutes what I will call a temporal perspective for the subject. Thus, on the B-theoretic conception, subjects of temporal experience have a number of successive temporal perspectives (that is, temporal perspectives that are related to each other by the B-relation of succession): their lives are spanned by a large number of momentary experiences that stand in the succession relation to one another, each of which has a content that is largely characterised by the subject's tensed beliefs, perceptions and actions, memories and anticipations, at that time. When thinking about this point in abstract terms, it is easy to miss the experiential significance it has for a subject of temporal experience. At a given time, what the subject perceives then, does then, and thinks then, to a large extent shapes the content of the momentary temporal experience (s)he has then. That is, each temporal perspective is in some sense experientially centred on its time. There are at least three ways in which this is so.

First, what we anticipate/imagine and whether to consciously recall past events is up to us to a much larger degree than is whether and what to perceive at any given time. The present looms large in our experience partly because we can't escape it: we could stop anticipating or recalling events, perhaps, but we cannot stop perceiving as long as we undergo experiences at all, and what we perceive isn't up to us in the same way as is what we anticipate and/or recall.

One might imagine [as Barry Dainton does in a slightly different context (2000, p. 124)] being given a drug which over the course of a day gradually destroys one's experiential memory without impairing one's mental functioning in any other way. First one loses one's early childhood memories, then one's school years, then one can only remember a day back, a minute, a second-but one continues to be conscious. It seems conceivable that in such a situation one's short-term experience of time would be much as it ever was. In this sense, our memory of other times is not as dominant in shaping the content of each momentary experience as is our experience of events then. Similarly, one could in principle, and perhaps does at times, cease being concerned with or anticipating events at future times. What we perceive at any given time, however, is not so easily subtracted from the content of our momentary temporal experiences. Any momentary experience involves perceptions, and what we perceive at any given time is mostly restricted to events that occur at that time (or rather slightly earlier). That is, each momentary experience is characterised by a temporally limited perceptual horizon. ${ }^{1}$

\footnotetext{
1 See Le Poidevin (2007, p. 85) for a B-theoretic explanation of our temporally limited perceptual horizon.
} 
Second, at each time, we make decisions and initiate actions at that time. Whatever one's view of decisions and actions, they undoubtedly loom large in any given momentary experience. And while each experience involves its own decisions and actions, at any given time, the decisions and actions taken at that time are the most experientially significant to the subject.

Third, depending on one's view of each of these aspects of experience, i.e. of perception, decision making, memory and anticipation, one may think they all to some extent involve beliefs. And it is indexical beliefs, so in the case of time tensed beliefs, that are crucial. We do of course have tenseless beliefs about appointments, history, shop opening hours, how long various activities take etc. But most of our conscious mental life is shaped by occurrent tensed beliefs, and tensed thought is temporally perspectival, the relevant perspective being that of the time we are at.

Fortunately, B-theorists have a view of tensed language at their disposal that allows them to think of tensed thought as true if had at the right times [see e.g. (Oaklander and Smith 1994)]. On such a view, there is nothing at all mistaken about our tensed beliefs (provided we have them at the right times). They are simply our way of keeping track of our temporal perspective. Because of this, the experiential significance of temporal perspectives that derives from the perspectival nature of tensed beliefs is well-grounded on the B-theoretic view.

To all this it might be objected that often, we are much more concerned with what happened to us yesterday and what will happen tomorrow than we are with what's happening to us presently. This is probably true, but it is quite compatible with the claim I am making. For one thing, in a B-theoretic framework 'the present' is a context-dependent concept. It picks out the time of utterance, but that time may be an instant, or an interval of varying temporal extent centred on an instant. So our concern about yesterday and tomorrow can still be a concern with the present - that is, the present week and month and year. Moreover, it seems fair to say that we are not typically as concerned with distantly past and future events as we are with those closer to the time we are at. Relatedly, even in our concerns about the past and the future, the present plays an important role: the reason yesterday concerns me in a particular way now is that it is one day past with respect to the time I'm at; similarly, the reason tomorrow concerns me in a particular way now is that it is one day into the future of this time.

These considerations show how phenomenologically rich, even though metaphysically lightweight, temporal perspectives are on the B-theoretic conception. At each time, that time seems special to us, and that sense is not at all misleading-it doesn't involve any mistake about temporal reality. Rather, it points to ways in which each time really is of special importance to us when we're at that time.

The next thing to note is that, because we remember earlier times, and our experiences then, we are aware that previous times felt just as special to us then, and anticipate that later times will do so too. Now consider John Doe's experience at dinner time on November 18th, 2010. Not only does that time matter especially to John then, but he remembers feeling the same at earlier times. For example, he remembers sitting at his desk at 3 o'clock that afternoon and spilling coffee. He also remembers that, at that time, he had future-tensed beliefs about dinner but no memories about any times later than 3 o'clock. 
So John at dinner time notices that time has 'moved on' - that is, he notices that dinner time is the time he is at then, and that there are $\}$ earlier times which he also experienced. Moreover, he quite rightly notices that his being at dinner time then is not the result of any of his actions: none of the things he did between 3 o'clock and dinner brought it about that he would exist at dinner time. Of course, they at least didn't interfere with his existence at dinner time, and by looking after himself, he contributed to his continued existence. But that dinner time that day is a temporal perspective that figures in John's life, i.e. that he exists then, he only finds out at dinner time, and it is not something he brought about. So, not only does he feel as if he is constantly 'moving towards' the future, but he feels a certain passivity in this respect; he feels as if he is 'being taken' to later and later times. And the same goes for the rest of us.

We do not feel the same passivity with respect to space. What is the relevant disanalogy? Jonathan Lowe has suggested that the relevant difference between time and space amounts to this: "in all the possible space-time routes a person may take the order of temporal positions will be the same, while the order of spatial positions may vary" (1987a, p. 69).

Robin Le Poidevin and Hugh Mellor have objected that this is trivially true.

[T] he truism that the time on a route must differ at different times on it (whereas the place may or may not differ) is as trivial as the truism that the place on a route must differ at different places on it (whereas the time may or may not differ). (1987, p. 537).

We have indeed a wider choice of places than of B-series times to put into or to leave off our space-time routes [...] The real reason is that our routes are continuous and that time, unlike space, has only one dimension. This means that while we can to some extent choose how long to live, we cannot choose to leave off our route any time between our birth and our death; whereas the greater dimensionality of space not only lets us limit the number of places we visit, but also lets us bypass any given place between two others without making our space-time route discontinuous. (1987, p. 537/8).

Lowe, in turn, responds as follows:

[O]bviously if we consider all of the space-time routes which a person might take, and put all of the distinct temporal positions in each such route into a temporally ordered sequence, then we shall find just one such (maximal) temporal sequence of which all the others are sub-sequences. This just reflects the fact that time is one-dimensional. [...] But [the original explanandum] has much more substantive implications than this. It implies, for instance, that if $<(\mathrm{s} 1, \mathrm{t} 1),(\mathrm{s} 2, \mathrm{t} 2),(\mathrm{s} 3, \mathrm{t} 3),(\mathrm{s} 4, \mathrm{t} 4),(\mathrm{s} 5, \mathrm{t} 5), \ldots>$ is a possible space-time route for a person, then $<(\mathrm{s} 1, \mathrm{t} 1),(\mathrm{s} 2, \mathrm{t} 2),(\mathrm{s} 3, \mathrm{t} 3),(\mathrm{s} 2, \mathrm{t} 4),(\mathrm{s} 1, \mathrm{t} 5), \ldots>$ may also be a possible space-time route for that person, but $<(\mathrm{s} 1, \mathrm{t} 1)$, (s2, t2), $(\mathrm{s} 3, \mathrm{t} 3),(\mathrm{s} 4, \mathrm{t} 2),(\mathrm{s} 5, \mathrm{t} 1), \ldots>$ is not. (Lowe 1987b, p. 542). 
What should be said about this exchange? It seems to me that the particular sequences to which Lowe draws our attention are significant, not because they are temporally ordered, but because they are causally ordered.

Calling the ordering 'spatiotemporal' is not to the point. What matters is the causal ordering of spatiotemporal perspectives. And the fact that in a causally ordered sequence, the temporal coordinate of elements monotonically increases is significant; it reflects the fact that the temporal dimension of space-time is the causal dimension.

Lowe is right to insist that the mere multi-dimensionality of space versus the mono-dimensionality of time does not, by itself, explain all of the relevant disanalogies. For, suppose that space was also mono-dimensional. Then the sequences Lowe considers would still all be such that the temporal coordinates of the elements monotonically increased throughout the sequence, while their spatial coordinates need not. The elements are ordered according to their causal relations, and those relations hold between elements with adjacent successive temporal coordinates that monotonically increase. The disanalogy between time and space arises because the temporal dimension of space-time is its causal dimension.

With this point in mind, consider again the B-theoretic conception of subjects of temporal experience. Human action is a causal process. When, at a given time, we make a decision or initiate an action, its most immediate effects are located at that time, and its less immediate effects are located at later times. If we could trace the effects of a given decision back to that decision via a series of intermediate events, so that we could identify the causal chain leading from the decision to its last effect (assuming for simplicity that there is one), the resulting sequence of events would be one whose elements exhibited monotonically increasing temporal coordinates. Their spatial coordinates need not exhibit such a pattern. This means that whatever we decide to do or not do, and in whichever ways we act, there is one constraint on the sequence of temporal and spatial perspectives that we can take up during our lives: each time (during our life time) will figure in exactly one element of the causal sequence of elements that is constituted by our lives' events, and the order of the elements will be their temporal order. That, very simply, is why we can do nothing to 'halt the passage of time', or to 'influence its speed or direction', i.e. why we feel we are being 'taken to' ever later times, independently of our own will. The reason is that what we can do is itself part of the causal order of events, and that order is also their temporal order. Our situation is different with respect to space: many of our actions bring it about that we move in space in a particular direction or that we stay in the same place. That is why we do not have the same sense of passivity with respect to space.

Thus, John Doe at dinner time on November 18th 2010 learns that that he exists at that time, i.e. that that is one of his life's temporal perspectives, and neither that fact, nor the fact that it is that time then, is the result of any of his actions. Moreover, he knows that at no earlier time was he in a position to choose to act in a way that would have resulted in time's changing direction or 'stopping', since any action of his is causally related to its effects, and thus temporally related to it by the relation of precedence (assuming that backward causation is rare and/or irrelevant in this context, if it exists). And similarly for any action that is open to him at dinner time. As a result of all this, he feels as though he is continually 'taken to' later and later 
times. And as for John, so for the rest of us. Our entire cognitive and emotional relationship to time is shaped by this fact that the temporal dimension of space-time is its causal dimension.

It is easy to dismiss this explanation as being simply based on a confusion because, like other B-theoretic accounts of veridical aspects of experience, it naturally borders on the trivial. But the point is noteworthy, contrary to what its description might suggest (how could this not be our temporal perspective nowhow could it not be now, now?), because of its experiential, as opposed to its metaphysical (e.g. ontological), significance.

Our feeling of passivity with respect to time, our feeling of 'getting taken' to later and later times, is at the heart of our experience of time as passing, and thus at the heart of our experience of time per se. Explaining why we should have it, and why we are right to have it, is crucial. The above facts can ground a veridical sense of time as passing, on the B-theory.

One might respond to this suggestion in one of three ways.

The first is to claim that the account somehow presupposes that there is objective passage, or objective 'moving through' time. ${ }^{2}$ Admittedly it would be easy for me to accidentally presuppose this since I believe that B-theorists include passage by positing succession. However, the above does not, I think, presuppose this in any way. All that the explanation relies on is that there is a succession of temporal (and spatial) perspectives, that human action is a causal process, and that the temporal dimension of space-time is its causal dimension. What I have tried to do is simply to draw attention to the experiential significance of these facts, i.e. to the experiential significance of temporal perspectives and their constituting a causal sequence. If am right to think that these facts alone ground a sense of passivity with respect to time, the B-theory alone, as commonly understood, grounds such a sense.

Next, one might object by asking whether, even if the B-theory does ground such a sense, that sense should be said to be veridical, i.e. to correspond to (an) aspect(s) of temporal reality presented by it. The objection is driven by the following thought: what B-theorists would like to do is to show how such B-theoretic facts as these give rise to a sense of something that is not objective, i.e. of passage; that is the point of such explanations. I agree that that is the stated goal of most B-theoretic explanations of our sense of passage, but such explanations seem to me to mis-characterize their own nature. While claiming to explain away, and thereby to expose as illusory, key aspects of experience, B-theorists such as Mellor $^{3}$ and Falk ${ }^{4}$ merely explain how these aspects of experience arise, without giving us any reason to think those aspects are not, on their theory, veridical. Of course it is open to any B-theorist to provide an explanation of an aspect of experience and then to add that the aspect in question is in fact illusory (and preferably to explain why); but this step is not obligatory. Unless the explanation itself gives us reason to think that something is being explained away, we need not also claim that the explanandum involves an illusion. The above explanation does

\footnotetext{
2 Thanks to an anonymous referee for voicing this objection.

3 (Mellor 1998).

4 (Falk 2003).
} 
not give us any more reason to think this than do Falk's and Mellor's accounts. ${ }^{5}$ The account I discuss in the next section does give us reason to think this; I deal with it separately.

Which brings us to the third potential objection: something is still missing. Perhaps some sense of passivity can be explained in this way, and perhaps it can be taken to be veridical on the B-theory, but, and perhaps especially if it can be, this is not all there is to our experience of passage. There is a key aspect of our experience of time as passing that has not been touched on.

\section{Our Perception of Succession in Question}

Let's face it: if one thinks that the B-theory clashes with how we experience time, because we experience time as passing, one is going to think that that aspect of experience is so ubiquitous, so central to all our experience, that what is still missing is, everything. If there is some kind of dynamicity in experience that the above conception leaves unexplained, then the above picture is radically impoverished, or radically revisionary, or both. But why think this-what exactly is this ubiquitous feature of experience?

B-theorist Le Poidevin writes:

The most problematic data to interpret concern the experience of succession: seeing a bird flying overhead, hearing a musical phrase, feeling the rain on one's face. It is this kind of experience that seems most clearly to intimate the passage of time. (2007, p. 10).

Le Poidevin defends what he calls 'projectivism', about both presentness and passage. The claim is that while A-theorists have correctly identified certain salient features of our temporal experience, they have allowed themselves, presumably along with all non-philosophers, to be systematically misled by these features. The mistake lies in taking these aspects of experience to correspond to aspects of temporal reality, and the mistake is a natural one to make. But it is a mistake. The project, then, is to try to explain away what are conceded to be pervasive aspects of temporal experience.

Consider the 'phenomenological paradox', which is the philosophical puzzle as to how we can perceive temporal extent. Le Poidevin expresses it as follows. While we perceive change and motion, and while this must involve our perceiving objects at two different times, we also only perceive things as present, and the present (we assume) is instantaneous. It is not that we perceive only things that are present, or even roughly present; rather, the problem is that we only perceive things as present. How can this be, given that change takes time? Le Poidevin's answer is a version of the memory theory. That is, he utilizes the notion of memory to explain how we experience temporally extended contents, rejecting the idea that we are ever directly aware of a temporally extended content.

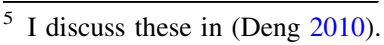


What gives rise to the experience of pure succession [...] is the conjunction of the perception of E with the very recent memory of C. (2007, p. 89).

As Le Poidevin rightly points out, this resolution of the puzzle favours neither the A-theory nor the B-theory. What is remarkable is that right after noting that "there is nothing in these data to incline us towards the A-theory", Le Poidevin argues for the following claims on the basis of certain empirical findings (see below):

[T]here is at least a component of motion perception that is constructed, or projected, by the mind. Further, [...] there are cases where the mind projects motion where there is none. So when the A-theorist points to the fact that we just perceive motion in the world, as support for the notion that time passes, we should note that this is not always a datum that is simply forced on the passive mind by external circumstances, but is actively constructed, at least in part. It does not follow that motion is always projected. [...] But it is salutary to reflect that the perception of motion is more complex than it might appear, and this should encourage anyone to exercise some caution in framing arguments from experience in favour of the A-theory. (2007, p. 95).

In my view, pointing to the complexity of the perceptual mechanisms involved in defense of the B-theory is the wrong response. When "the A-theorist points to the fact that we just perceive motion in the world, as support for the notion that time passes", instead of noting "that this is not always a datum that is simply forced on the passive mind by external circumstances", and that "the perception of motion is more complex than it might appear", we should remember that the idea that there can be change, e.g. motion, without tensed facts or a non-perspectival present, is central to the B-theory. Why then should B-theorists deny that we perceive these things? What reason is there to suppose that if change in the B-theoretic universe poses no special problem, our perception of change does?

Contrary to what the structure of Le Poidevin's chapter might suggest, his claim about our projecting motion and passage onto the world does not receive support from his discussion of our experience of presentness. ${ }^{6}$ It could do that only if our experience of passage had been shown to be in some way connected to our experience of the present, and no such connection is mentioned. In the end, the projectivist claim rests entirely on Le Poidevin's discussion of the following empirical findings. ${ }^{7}$

The first group of findings concerns the involvement of the brain in interpreting information from the eye/head and image/retina systems in motion perception (Le Poidevin 2007, p. 93). It seems that this process in part depends on information from the part of the brain responsible for controlling eye movement. For example, when the eyeballs are prevented from moving, but the subject attempts to move them, the brain incorrectly registers motion (of external objects). The second group of findings

\footnotetext{
${ }^{6}$ In fact, that discussion barely licenses the conclusion that we project presentness onto the world, if that is understood as the claim that our perception of events as present involves some widespread error. I argue for this claim in 'On explaining why time seems to pass' (manuscript), where I also examine Laurie Paul's (2010) and Simon Prosser's (2013) proposals.

7 See (Phillips 2009) for references to related empirical findings.
} 
concern the so-called flash-lag phenomenon. Here, subjects are presented with a moving dot on a screen, and a second dot that appears very briefly above or below it. In a significant number of cases, subjects report that they saw the second dot behind the moving one, instead of above or below it. There are different suggested explanations. But often, the explanation involves active interpretation on the part of the brain, based either on the previously registered movement of the dot (predictive model), or, even more strikingly, on its subsequently registered movement (postdictive model).

It seems to me that interesting though these findings are, they do nothing to support the claim that we generally project motion and temporal passage on to the world. For one thing, active interpretative involvement of the brain in the perception of motion and of change is not straightforwardly a sign that these aspects of experience are misleading. Instead of taking evidence for such mechanisms to show that we project motion and change on to the world, we can just as well take it to shed light on what it is to perceive motion and change. Moreover, Le Poidevin has given us no reason to think our perception of succession poses any more of a problem on the B-theory than on other views of time.

Of course, that Le Poidevin gives us no reason to doubt the veridicality of our perception of succession does not show that there could be no such reason. But such a reason is needed. And note that, as Le Poidevin himself demonstrates, no such reason will be forthcoming simply on the basis of the puzzle of temporal phenomenology, i.e. the question of how it is possible for us to perceive temporal extent. That puzzle arises equally on other metaphysical views. Indeed, the traditional concern about the specious present may well have been motivated by a latent presentist ontology: if neither the past nor the future are real, how can it be that we are aware of temporally extended contents? ${ }^{8}$

Insofar as there is a puzzle about the nature of momentary experiences, then, B-theorists have no more of a problem with it than do A-theorists. That we see $a$ ball moving rather than two stationary images of a ball does not conflict with a single B-theoretic tenet. All the B-theory says is that the successive items, or events, giving rise to the perception, all exist; that similarly, the mental events caused by them exist too, and if there are several of them at different times, all of them equally; and that whether something is 'past' or 'present' or 'future' depends on one's temporal perspective. Finally, the B-theory adds the idea that this is all there is to temporal reality, i.e. that all other, all A-theoretic views, are mistaken. It does not claim that there is no such thing as temporal succession, nor that any two successive items ever exist simultaneously. This includes phenomenal items: if two tones are heard successively, that means they are precisely not heard simultaneously, nor in a special jerky manner, but rather one after the other. In the absence of a reason to think otherwise, we should expect that our perception of succession is no more problematic on the B-theory than is succession itself.

\footnotetext{
8 Thus, Shaun Gallagher writes: "[T]he specious present [...] is always conceived in this Jamesian tradition as a sensed or "perceived" duration that purportedly operates as a solution to what we have called "the problem of objective synthesis". That is, it addresses the problem of explaining how we can perceive objects as either changing or persisting over time, despite the fact that the past seems not to persist or have actuality." (1998, p. 18)
} 
And there is a more positive lesson here as well. If I am right to think that B-theorists can allow our perception of succession, including our perception of change and continuity, to be generally veridical, since it acquaints us with tenseless facts about the successive occurrence of events, and if, as Le Poidevin concedes to A-theorists, this aspect of experience really does involve dynamicity (and perhaps it does, if by 'dynamicity' we just mean the continuous happening of things, one after the other), then in this sense, too, we truly experience dynamicity on the B-theory.

\section{A Final Objection}

No doubt anyone who thought there was a problem in the first place will think that there is still something, and indeed still everything, missing from the B-theoretic conception. Thus, A-theorist Fiocco writes:

Causation [...] does not provide the means for an adequate account of temporal becoming [...] Consider, for instance, the phenomenological novelty of each moment (the continuous sense that one has not encountered this state of the world); this feature of our temporal experience is surely caused-but by what is exactly the point to be illuminated. $(2007$, p. 8$)$.

[I]f temporal reality were [B-theoretic], then there is no reason to think that one would ever be aware of a moment other than a single one, to wit, this one [...] [O]ne would still be in need of an explanation for why it is the case that successive uses of an expression are simultaneous with different sets of events, that is, why successive uses of an expression by a single speaker are even possible and how they occur at distinct moments. (2007, p. 7).

What should be said in response to this criticism? In a way such comments are hard to make sense of. What would it mean to only ever be aware of one time-does it mean being at all times only aware of one time? And what does that mean? And why should this curious state of affairs be a consequence of time's being B-theoretic?

The 'phenomenological novelty' of each moment concerns what it is like to undergo any experience at all, to be a live subject of experience. To be such a subject is, at any given time, to have a temporal perspective in the rich sense characterised above: it is to experience memory and knowledge asymmetries at that time, and to be bound with respect to one's immediate causal influences to that particular temporal region. In particular, each time involves gaining the knowledge that that time \{exists\} and that one's life \{continues at that time in a particular way. What that is like is known to all, and no theory of time worth its salt can deny that such experience exists or leave it out altogether. But the B-theory does not do that. It includes the rich notion of temporal perspective in play here.

A given temporal perspective may or may not involve explicit thought tokens, or utterance tokens, of the type 'this is new' or 'I haven't encountered this before'. If it does, there are two ways to interpret the belief types in question. First, the subject might simply be referring to the B-time they are at then. In that case, the tokens are 
trivially true, because one indeed \{does \}ot encounter that time at any previous time. Second, the subject may be referring instead to the experience they are undergoing then, and in particular to the experience's subjective nature as it is accessible to him or her. If so, the tokens would be reporting, not that the subject is currently located at a time they \{were $\}$ not located at at any previous time, but rather that they are currently undergoing a new experience.

Of course, not every momentary experience is qualitatively strikingly novel. But the phenomenon Fiocco describes does not depend on whether one is encountering novel sensations. Indeed, one might imagine a situation in which one's sensory input stays qualitatively exactly the same, though one continues to have repeated thought tokens of the types in question. This might even be a particularly pure manifestation of the phenomenon Fiocco has in mind. ${ }^{9}$

Thought experiments of this kind are to be handled with care, to be sure, but the following seems to be suggested by introspection: one can subtract everything from one's successive momentary experiences in this example without losing the sensation of novelty, except for short-term memory. In particular, while each experience can be exactly like the previous one, each one has to include an awareness of the succession of the previous one by this one. At each moment, one must be aware, through short-term memory, that this momentary experience, and one's current thought, is succeeding a previous, exactly qualitatively similar one. One need not remember how many moments ago the succession of similar moments began, or that one has been having the same kind of experience for a while now. But one does need to remember the previous thought token, when having each new one. That is what grounds the sensation, i.e. the awareness, of novelty, at each moment: one notices that this moment is succeeding the previous one, that a 'new', i.e. 'an other', moment is happening.

It would seem as though the phenomenon in question is entirely compatible with the B-theoretic conception. At each moment, one is aware that one has not encountered 'this' state of the world before, because one remembers having just encountered a numerically different, though qualitatively identical state. If one has explicit thought tokens of the type described, then those tokens will be true, if 'this' refers to a particular state or experience, or false, if 'this' refers to a kind of state or a kind of experience; but in any case, the sensation of novelty will be entirely appropriate, and just as predicted by the B-theoretic conception.

Fiocco's objection, then, is unfounded. But I think it's an expression of a very natural way of thinking. Elsewhere ${ }^{10}$ I have called this 'our intuitive picture of passage': we think of ourselves as moving into the future, of events as becoming less and less future, or of times or events as continually coming into and going out of existence. In thinking of each moment as 'novel', we think of it as privileged namely, as the latest, or the most real moment. The reason we are dissatisfied with the B-theoretic conception, and any B-theoretic attempt to ground a veridical sense of passage, is that only a metaphysically fundamental sense of 'novelty' will do. This moment seems 'new', not just in the sense that I \{do\} not encounter it any

\footnotetext{
${ }^{9}$ I am indebted to Oliver Pooley for this example.

${ }^{10}$ (Deng 2013).
} 
other time, but in some metaphysically fundamental sense. It has just been 'added' to the sum total of reality.

These are of course paradigmatically A-theoretic images, but there is no denying that we all have a tendency to think of time this way. However, when one examines this way of thinking more closely, one finds that it rests on two essentially opposed intuitions. The first is the intuition we have at each time, that this time is metaphysically privileged; and the second is the intuition we have at each time, that other times are fundamentally on a par with this time. Elsewhere, I have argued that the lesson to draw from McTaggart's (in)famous argument is not that time does not pass, but rather that this way of thinking of time and its passing is incoherent, and thus without literal content. Time passes, but all that can literally mean is that there is a succession of times, one after the other — and the B-theory already acknowledges that.

\section{Conclusion}

I have tried to show that the B-theory straightforwardly grounds a veridical sense of passage.

I began by arguing that the B-theory predicts that subjects of experience have a sense of passivity with respect to time that they do not have with respect to space, which they are right to have, even according to the B-theory. All the explanation relies on is that there is a succession of temporal (and spatial) perspectives, that human action is a causal process, and that the temporal dimension of space-time is its causal dimension. These facts are of experiential, as opposed to metaphysical, significance. If am right, then the B-theory alone, as commonly understood, grounds a sense of passivity. That sense of passivity, I argued, should be taken to be veridical on the B-theory.

I then asked what else might be involved in our experience of time as passing. I examined Robin Le Poidevin's explanation of our 'illusory' sense of passage on the B-theory. I argued that his proposal explains away too much: our perception of change poses no more of a problem on the B-theory than it does on other theories of time. The upshot was that if there is dynamicity involved in our perception of succession, then it too is a veridical aspect of experience on the B-theory. The B-theory grounds a veridical sense of passivity with respect to time, and a veridical perception of change. Finally, I responded to an objection by Oreste Fiocco that a causal account of our sense of passage cannot succeed, because it leaves out the 'phenomenological novelty' of each moment.

Acknowledgments Thanks to Oliver Pooley for extensive discussion of these issues. Thanks also to Antony Eagle and Robin Le Poidevin for their comments. Part of this work was carried out while I was a member of the Swiss National Science Foundation project "Intentionality as the Mark of the MentalMetaphysical Perspectives on Contemporary Philosophy of Mind” (Sinergia, CRSI11-127488).

\section{References}

Dainton, B. (2000). Stream of Consciousness: Unity and continuity in conscious experience. London: Routledge.

Deng, N. (2010). Beyond A- and B-time Reconsidered. Philosophia, 38(4), 741-753. 
Deng, N. (2013). Fine's McTaggart, temporal passage, and the A versus B-debate. Ratio, 26(1), 19-34.

Falk, A. (2003). Time plus the Whoosh and Whiz. In A. Jokic \& Q. Smith (Eds.), Time, tense, and reference. Cambridge: Massachusetts Institute of Technology.

Fiocco, O. (2007). Passage, becoming and the nature of temporal reality. Philosophia, 35(1), 1-21.

Gallagher, S. (1998). The inordinance of time. Evanston, Illinois: Northwestern University Press.

Le Poidevin, R. (2007). The images of time: An essay on temporal representation. Oxford: Oxford University Press.

Le Poidevin, R., \& Mellor, D. H. (1987). Time, change, and the 'indexical fallacy'. Mind, 96(384), 534-538.

Lowe, E. J. (1987a). The indexical fallacy in McTaggart's proof of the unreality of time. Mind, 96(381), $62-70$.

Lowe, E. J. (1987b). Reply to Le Poidevin and Mellor. Mind, 96(384), 539-542.

Mellor, D. H. (1998). Real time II. London: Routledge.

Oaklander, N., \& Smith, Q. (Eds.). (1994). The new theory of time. New Haven: Yale University Press.

Paul, L. (2010). Temporal Experience. Journal of Philosophy, 107(7), 333-359.

Phillips, I. (2009). Review of Robin Le Poidevin's 'the images of time'. British Journal for the Philosophy of Science, 60(2), 439-446.

Prosser, S. (2013). Passage and perception. Noûs, 47(1), 69-84. 